\title{
THE IMPLICATIONS OF CHANGE IN SOUTH AFRICAN SOCIETY FOR THE HEALTH PROFESSIONS
}

\author{
Hentie Boshoff
}

To address this problem, one has to look at (i) societal changes and future developments, (ii) changes in health care as such and (iii) the linkage between these two. In this respect we must realize that we are living in an era where economic, technological, demographic, social and political changes are accelerating. The interface between these changes results in the age of discontinuities as far as individual trends are concerned. To work therefore with projected futures amounts to brain gymnastics.

A more realistic approach is to define the key drivers or trends and structures shaping the future of society and health care, and from this deduct the possible implications for health professions.

Societal key drivers affecting change The process of societal change evolves around economic, technological, demographic, political and societal change

\section{ECONOMIC CORE DRIVERS}

Our exports must shift from a raw material base towards high tech and mineral benificiation

The industrial economies is becoming uncoupled from raw materials and labour due to better design, microchip, artificial metals and minerals, computer assisted design and production and micronization. Unless we can effect this changeover before 1995, chronic balance of payments problems, lower economic growth, less employment opportunities and therefore less public and private funding for health care will result. Because it will be a capital intensive process, it will form the wealth creating part of our economy, and not the job creating part.

\section{Growing inability to sustain a high} economic growth rate

The slowdown of further growth in import substitution, the lower growth rate in industrial economies, our lower exports of raw materials due to lower demand in industrial countries, the unfriendly external political environment, our low internal savings rate and shortage of skilled labour more and more results in a growth rate not exceeding $3 \%$ per year.
Employment and health funding will suffer likewise.

Demand and production structure will shift towards basic/Black demand Up till now Whites received the dominant share of disposable income; they therefore dominated the market. Due to a lower white birth rate, saturation of the white market for especially durables and a lower growth rate in income, the internal market will have to shift towards the Black market. They have the numbers, but not the income. The expected lower growth rate will not enhance the income redistribution process materially. Basic needs (especially of Blacks) instead of luxury needs will form the backbone of the market. This also implies for health care.

Inability of enough employment creation in formal/modern sector We need to create about 1000 new jobs per workday to absorb all potential work seekers. To succeed, we need an economic growth rate of $6 \%$ per year. This means we are heading towards a situation where 40 $50 \%$ of our people will have to be employed outside the formal/modern sector of our economy. The informal sector and inward industrialization will form the job creation part of our economy. The health implications of this is that many people will not be formally employed, belong to medical benefit or have a sustainable income.

Emphasis must shift from economic demand or population ratio to health or biological needs health model

We lack a medical care system in which government is relatively uninvolved while the private sector carries the bulk of health services as well as a small rich/poor imbalance to sustain an economic demand model for health care for all people in this country. We also do not have the money to sustain a population ratio model; at least not one based on First World ratios. A health or biological needs model taking into account available technology and finance, what kind, amount and quality levels of services are required to attain and maintain a healthy population will more and more become the order of the day for the bulk of the population. Fulfilling health ethics by providing services according to needs and not according to social or economic conditions of consumers will mean that the emphasis must shift from remedial/curative to
primary/preventive health care. To a larg extent the economic need model will apply to those who can pay for it.

\section{TECHNOLOGICAL KEY DRIVERS} Information and biological revolution can surpass industrial revolution

We are witnessing two changes that can surpass the industrial revolution of the previous century in scope and magnitude. It started with the computer, progressed towards micro electronics, and with the aid of optical fibres, is entering the information era where national and international networks of info becomes interlinked. The development of computer assisted medical technology such as MRI (magnetic resonance imaging scan in which tissue and no bones appear), CAT scan, a SONO scan (computerized reconstruction of sound waves beamed through the body) as well as computer assisted information storage, retrieval and distribution of hear. care knowledge will become the order of the day to survive in health care professions. The second revolution that will grow in the next 10 years is biotechnology. It is aimed at redesigning of living organisms for use in (i) plant manipulation, (ii) animal manipulation, (iii) health manipulation (a shift from chemical based medicine towards a body chemistry base) and (iv) materials manipulation to design synthetic fibres and materials. The resultant advances in medical and medicine technology will have an important effect on the structure of health care in that preventive health care will grow.

\section{New drug delivery systems}

Advances in biotechnology will result in new drug delivery systems and more specific on targeted drugs. Drugs will be introduced into the body by implants, skin surface devices, controlled release mechanisms and microcapsulation that will allow more precisely targeted and 
consistent delivery of pharmaceuticals. Constant monitoring of results and side effects will become an important part of health care.

\section{DEMOGRAPHIC KEY DRIVERS}

Black fertility rate is unacceptably high

The White natural growth rate is heading towards below the replacement rate. The Coloured and Indian rate is also falling. The Black fertility rate is still very high. The difference between a replacement fertility rate at 2015 and 2050 in terms of numbers is shown in graph 5 . The extra cost of this difference as far as medical care is concerned is estimated at $R 670 \mathrm{~m}$ per year by 2020 in real terms, while that for education will be $R 2000 \mathrm{~m}$ in 2020 . We cannot afford it. Furthermore, the carrying capacity of the land in terms of water is estimated at 80 million people. A preventive health care programme, integrated with an economic development and education programme, will be vital for survival.

\section{An ageing White and a young Black population}

This is the result of the differences in birth rates. The results are shown in graphs 1-4. White health care will shift towards the aged and chronic illnesses, skin care, eye impairments, etc. To a lesser extent this will be the case among the Indians and Coloureds. The opposite will happen among Blacks, unless their fertility rate can be lowered. The mean age of Blacks are now entering the high reproductive age. Child care and allied diseases will dominate.

\section{Political key drivers}

We can determine three forces at this stage. The first is the revolutionary takeover of power force; mainly at the far left a the political spectrum. The second is the ribution of power force, mainly to the right of the political spectrum. The third is the power sharing force as the only evolutionary force. These forces result in the see-saw scenario in the sense that if we do not have development, job creation, etc., the balance might shift to one of the extremes.

\section{REGIONAL CHANGE KEY DRIVERS} The second "Great Trek"

Economy and population wise our society is moving in a northerly and north easterly direction. Transvaal and Natal is benefiting, while the southern part of the country is suffering. Unemployment, lower income and fewer facilities will result in stretching health facilities to the limit.

\section{Mass urbanization of Blacks}

The White, Coloured and Asian urbanization process is more or less completed in the sense that these groups have a $90 \%$ urbanization rate. At present only $40 \%$ of Blacks are urbanized; the majority in the
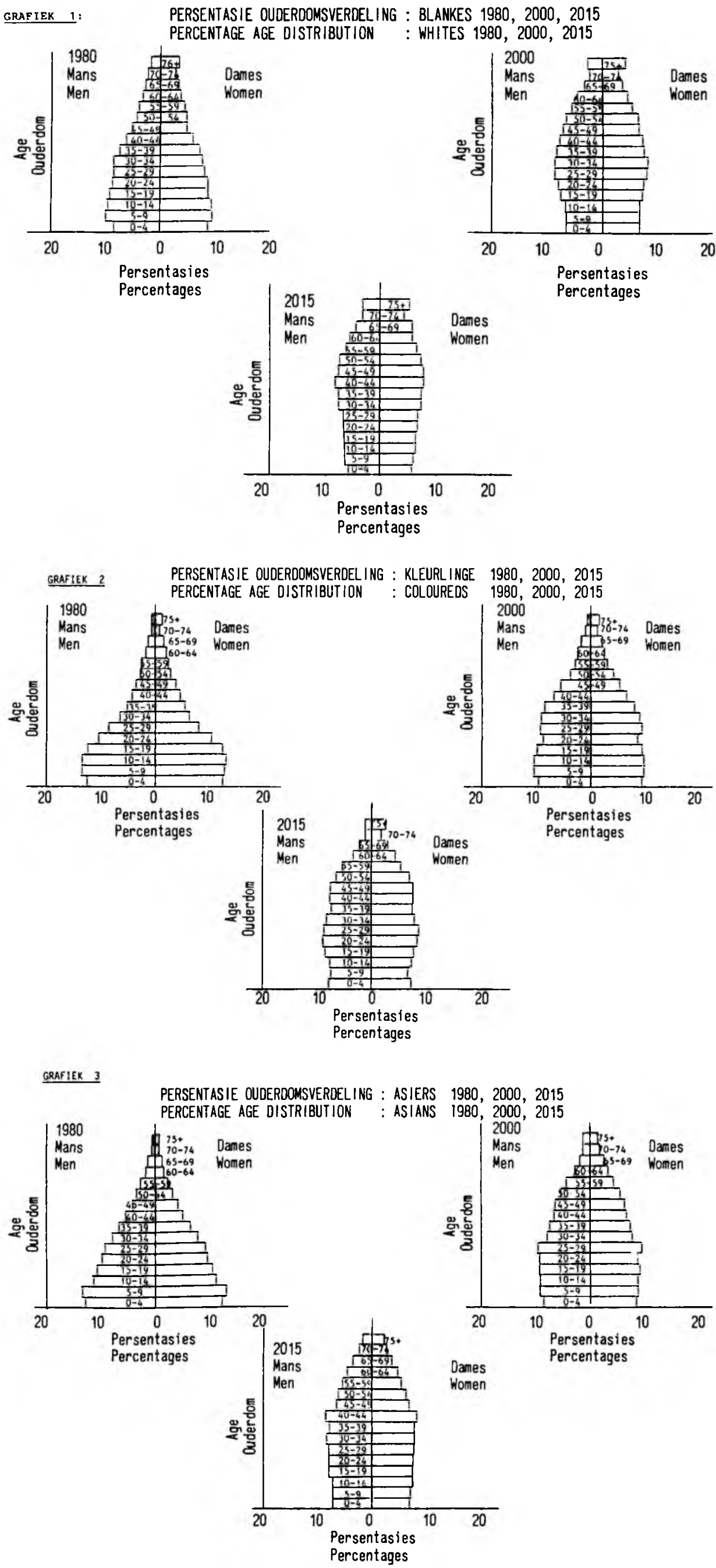


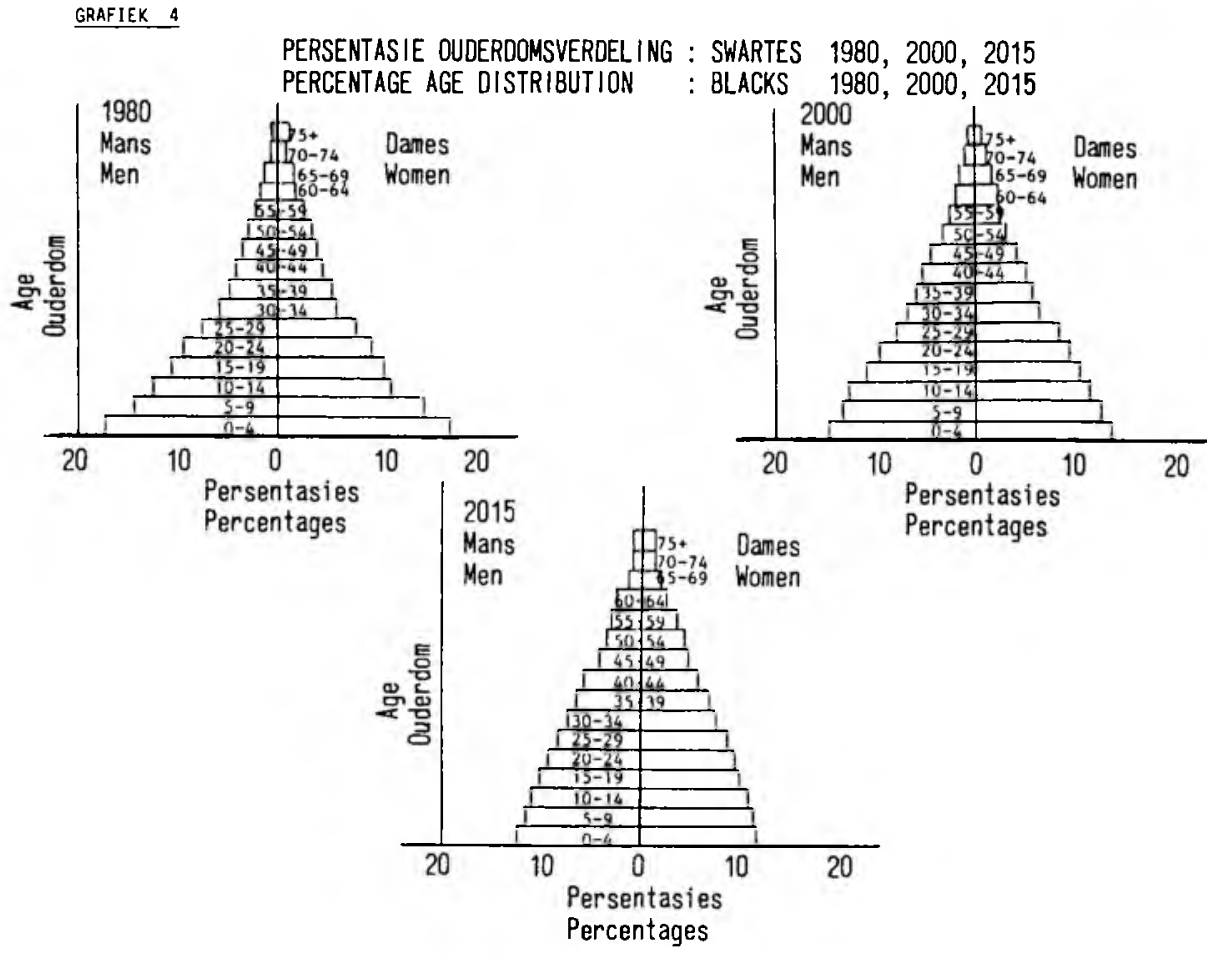

so called White RSA. The scrapping of influx control and the pulling power of job opportunities in the cities will raise this figure towards $70 \%$ by the end of the century. This means an additional 12 million + extra people in the cities and first order growth towns. The health implications, especially as far as preventive health care is concerned, are staggering.

\section{Integrated First and Third World}

Historically the towns and cities in the white areas were the First World, whilst the rural and Black areas were the Third World. Due mainly to urbanization this is becoming an artificial demarcation. More and more both worlds will become interwoven in the cities and towns as far as the economy, population and services needed, are concerned. The full spectrum of health care facilities will have to be provided, especially in the cities. A quality distinction between the services of both worlds will also be artificial.

\section{Health care key drivers \\ Cost of health care escalates beyond control}

The real per capita outlay of government and health services are rising too fast, as shown in Table 1. The big increase is not in the Department of Health itself, as their work is mainly preventive in nature, but rather at the provincial level whose focus is mainly remedial in nature. The latter increased by $39 \%$ from $1970-1984$, whilst real GDP rose only by $11 \%$. The real per capita outlay on government health services even exceeded the growth in the private sector.

The result of this will be twofold. The first is a movement away from the emphasis on remedial care and the laboratory centered health care and training towards a preventive/primary or community health care and training approach. The second is privatization of medical services. For this to succeed, the cost of medication and medicine must be lowered through new structures. The present private sector structures are too expensive to accommodate government patients. $\mathrm{CHC}$, group practices, etc. is unavoidable.

\section{Self-medication}

Medical apparatus is becoming smaller, portable, cheaper and easier to handle. Computer diagnostic systems, the so called smart card health record and hospital on your wrist is a growing phenomenon. The treatment of chronic diseases such as asthma, ulcers, arthritis, diabetes, etc., move more and more towards the end user in the sense of self-diagnosis and medication. The growth in patient-ready packs medicine, coupled with national advertising, will enhance this trend.

\section{Alternative health care}

Out of hospital services is in the take-off stage. Surgicentres, emergency care centres designed to receive critically ill people, urgent care centres that provide care for routine or minor surgery problems, occupational medicine clinics, pure form primary care centres, technology based home health care services, walk-in or urgy centres, will more and more form an alternative to hospital treatment. The reasons for this is threefold. The first is lower costs, as these centres are on average $40 \%$ cheaper than hospitals. The second is convenience coupled to technology. The third is a social response towards the clinical/ depersonalized big hospitals. High tech needs high touch to survive.

\section{Holistic health care}

In this approach the physical, mental, spiritual and emotional states are interrelated with each other and the environment. The focus is on prevention, teaching of basic self care skills to all, extensive home care support programmes, focus on outpatient rather than in-patient care, deemphasize role of physicians, group practices and community health centres Apart from the fact that health care peopiwill be more involved in giving advice, they will have to be a part of a group practice and have more knowledge of natural products such as homeopathics, spices and vitamins.

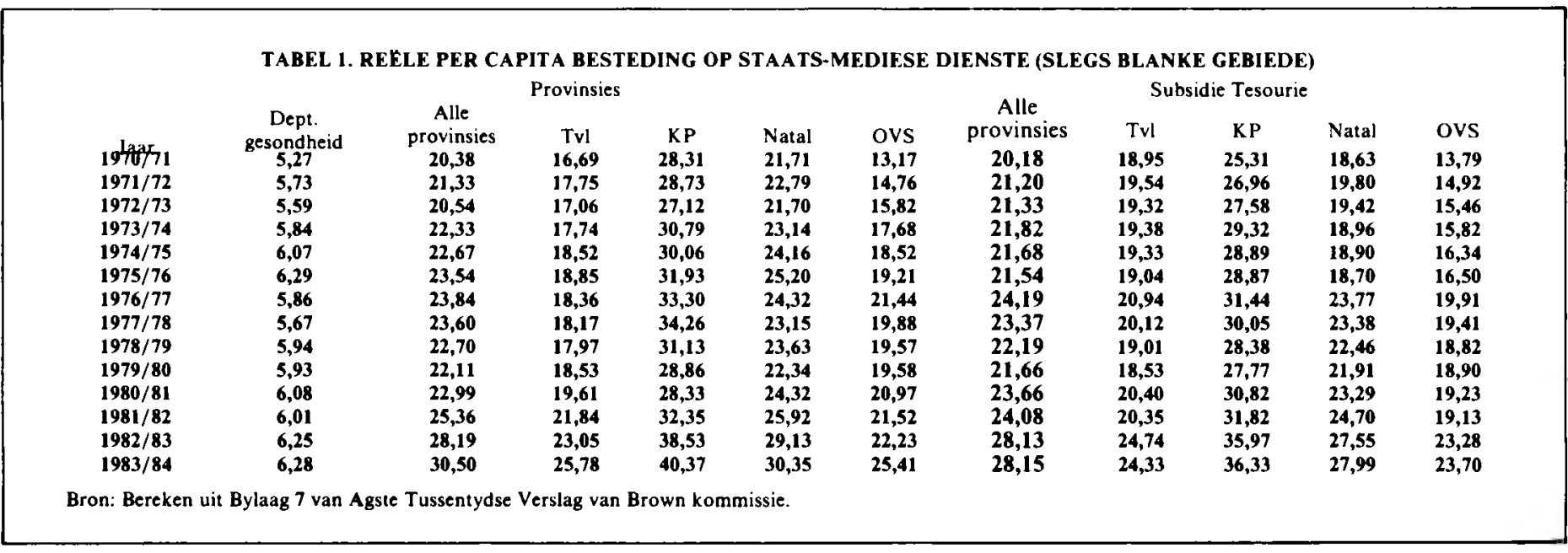




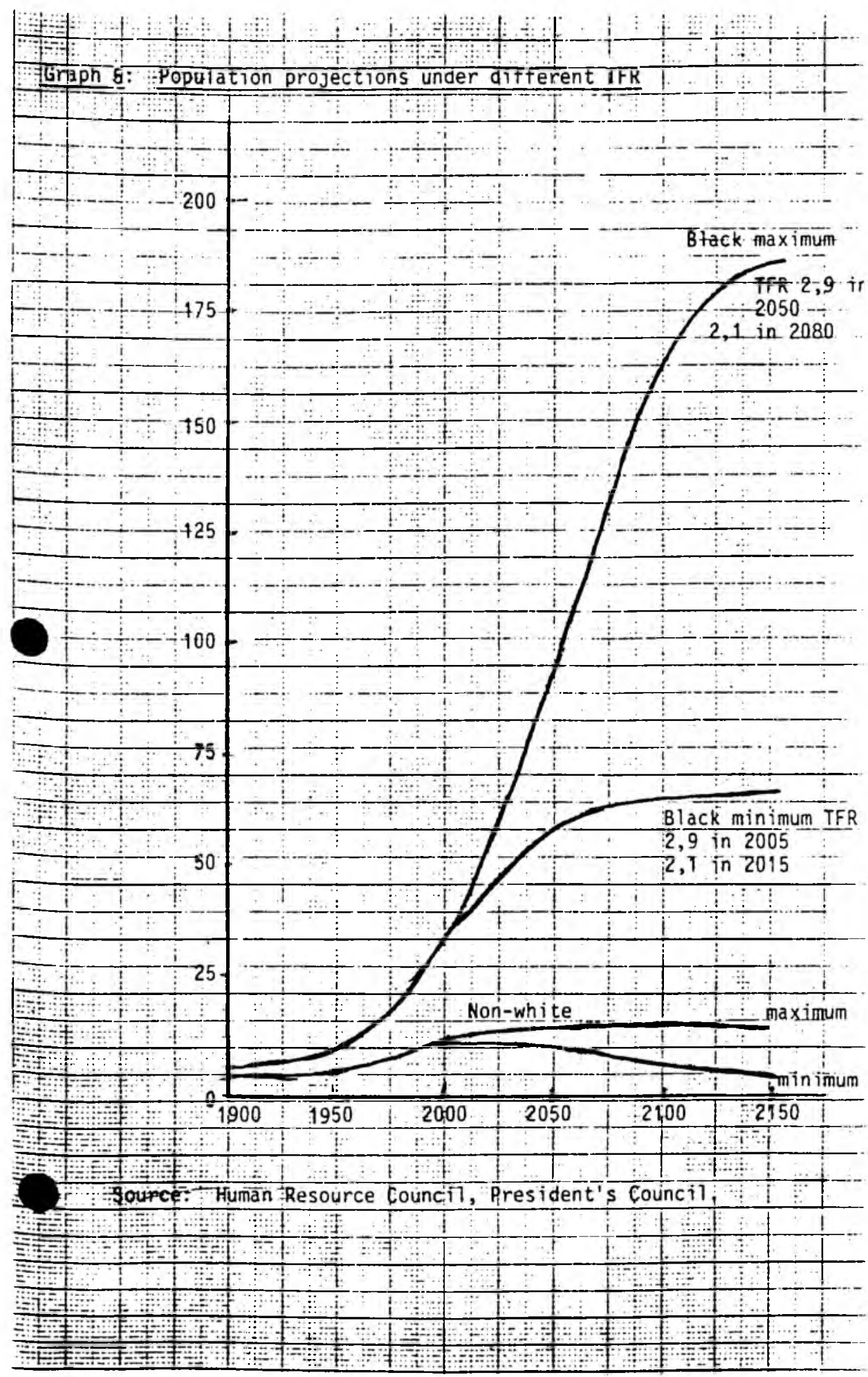

\section{Structures needed}

To accommodate these structural trends, a shift from primary remedial health care towards preventive/primary health care is needed. Also, a structure for lowering of medical and medicine cost is needed.

Preventive health care only makes sense if it is affordable. The following seems prerequisites for such an approach to succeed.

Low cost preventive care structures It is a known fact that $80 \%$ of clinic patients do not need a medical doctor, but can be treated by a nurse and a pharmacist. It is also known that $80 \%$ of primary/preventive care and remedial care The bulk of health workers will fall under the former and would not need the specialized knowledge needed by the remedial health care personnel.

\section{An integrated approach needed}

A survey done by the British "The Economist" has found that the primary health care approach of the WHO has failed in many African countries. Primary health care is above all an integrated package: it's measures reinforce one another, and in isolation each may have little effect. If, for instance, clean water and sanitation are not introduced simultaneously, immunization programmes may often result only in shifting the pattern of diseases. Many of the WHO programmes in Africa are fragmented because they are sponsored by different organizations and not co-ordinated.

\section{Group practices needed}

There are basically two reasons why participation of health workers in group practices, either as paid employees in a $\mathrm{CHC}$, or as an individual in a private practice, are needed and will grow. The first is that the holistic health concept cannot work without a multi-disciplinary approach. The health industry of the future will not mean simply the treatment of disease. The emphasis will be on early diagnosis and the maintenance of health. Medical care will be integrated into a system concept, embracing preventive and remedial medicine, food and diet, primary/preventive and remedial health care, physical activities such as biokinetics, preventive cosmetics such as skin care for the aged, etc. The second reason is that a preventive health care programme cannot work successfully without a multidimensional approach, as was shown by the African experience.

\section{Rescheduling of medicine}

Schedule 3 and higher medicine that is essentially of a preventive nature will have to be rescheduled to schedule 1 and 2 . In the same manner some schedule 1 or 2 medicines can be deregulated to OTC grouping for use by nurses, etc.

Restructuring medical benefit schemes At present they pay a percentage on prescription medicine. This enhances the remedial health care approach, often resulting in an unnecessary expensive treatment. It is common knowledge that $20 \%$ members of medical schemes is responsible for $80 \%$ of all claims. The basic problem is that they function as sick aid schemes instead of health aid schemes. It is necessary that their structures be changed to accommodate the following principles. First, that preventive health care, especially in industrial clinics on HMO basis, can also be claimed. Secondly, that a use tariff for everyday/normal claims and 
a risk tariff for abnormal claims, be instituted. The latter must fall in the category of medical insurance on which a member can earn a no-claim bonus if he lives a preventive lifestyle. Thirdly, that a basic list of medicine (BLM) must be instituted. Preventive health care and privatization can only be effective if we can lower the cost of medicine.

\section{Holistic training needed}

There are two reasons for this. The first stems from the holistic health and group practice needs. For a nurse to function successfully in such an environment, she must have a running knowledge of the other discipline' involved in the team.

The second reason is accelerated technological ch ige. The more change there is, the quick :r 'inowledge becomes obsolete. The more technique and specialised your training is, the bigger the danger of obsolete knowledge and machines replacing people. Also, the more specialized trained people need to be retrained virtually from scratch if technological change occurs, while a holistic or generalist trained person can be retrained on an "add on" basis. The high growth rate in specialized para-medical professions is a case in point.

H. Boshoff. D.Comm.

Professor, Institute for Future Studies Potchefstroom University 